\title{
HOMENS DA MONTANHA: CRISTÃOS NOVOS E A OCUPAÇÃO DO INTERIOR BRASILEIRO
}

\section{MOUNTAIN MEN: NEW CHRISTIANS AND THE COLONIZATION OF BRAZILIAN INNERLAND}

\author{
Daniela Tonello Levy*
}

\begin{abstract}
Resumo: Judeus Sefaraditas, descendentes dos convertidos em 1497, foram os pioneiros na descoberta do ouro e diamantes na América portuguesa. A instituição do Tribunal do Santo Ofício da Inquisição, trouxe drásticas consequências para a vida Ibérica, que a longo prazo arruinaram o comércio português, fazendo emigrar do Reino os mais prestigiosos elementos, prejudicando por muitos anos a produção nacional, destruindo famílias e negócios. A cultura judaica, florescente na Península Ibérica até o século $\mathrm{XV}$, apagou-se, e Portugal submergiu nas trevas da ignorância. Em São Paulo, os cristãos novos estiveram entre os desbravadores do sertão brasileiro, ultrapassando os limites do Tratado de Tordesilhas. Os habitantes da então inóspita Vila de São Paulo de Piratininga eram considerados inimigos da Espanha, por suas incursões ao sertão em busca de oportunidades econômicas. No interior, lutaram contra às Missões jesuíticas, a vida selvagem, fome, sede e finalmente se tornaram os primeiros a encontrar ouro no Brasil. Foram os primeiros a abrir estradas e fundar as vilas do ouro. Um marrano, Garcia Rodrigues Paes, foi o responsável pela construção do "Caminho do comércio" que encurtava a distância entre o Rio de janeiro, principal porto e a Vila de Ouro Preto. Os sefaraditas acreditavam estar seguros, nas montanhas e no interior do Brasil, mas a Inquisição formou uma rede de espiões encarregados de espionar e prender os cristãos novos.
\end{abstract}

Palavras Chave: Inquisição. Cristãos novos. Minas Gerais. Paulistas.

Abstract: The Sephardic Jews, descendants from the Jews converted in 1497, were the pioneers in the discovery of gold and diamonds in Portuguese America. The difficult life for the New Christians in Portugal after the establishment of the Inquisition, led a group of Marranos to leave for the New World, where they thought they would have freedom and new opportunities. In Brazil, one of the most sought regions was São Paulo, an inhospitable place populated by Indians, which served as the perfect refuge for the conversos, some of them became great explores. The hard life in São Paulo drove the "paulistas" New Christians to lead expeditions to the countryside in search of economic opportunities. In the jungle they fought against the Jesuits, wildlife, thirst, hunger until, finally, they became the first to discover gold. It was the fearless Sephardim from São Paulo who, facing dangers and difficulties founded the first gold villages. A Marrano named Garcia Rodrigues Paes built a road to Minas Gerais called "Caminho Novo" (New Way) or "Caminho do Comércio" (Commerce Way), which reduced the travel time between Rio de Janeiro (the main port in the colony) and the village of Ouro Preto's. The Sephardis believed to be safe, deep into the Brazilian backcountry, but the Inquisition formed a network of informers (familiares) and officers responsible for investigating and preparing cases of accusations against the conversos.

Key words: Inquisition. New Christians. Minas Gerais. Paulistas.

"Para entender a sociedade colonial é preciso conhecer a qualidade da gente que veio para o Brasil. Enquanto não soubermos quem foram esses homens, qual o seu "background", as razões que os trouxeram para a América, será impossível caracterizar esse mundo que se formou nos trópicos". Minha mestra, Anita Novinsky, costuma repetir isso como um mantra: foi a missão que ela recebeu de seu mestre Lourival Gomes Machado e que agora ela transmite

\footnotetext{
* Daniela Tonello Levy é doutora pela Universidade de São Paulo, pesquisadora do Centro de Referência sobre Inquisição Anita Novinsky - Museu Judaico de São Paulo. Email: <dtlevy@ uol.com.br>.
} 
para sua equipe. Suas pesquisas desbravaram um novo Brasil, um país subterrâneo, com costumes e comportamentos clandestinos. Cabe a nova geração de pesquisadores, seguidores da "Escola Novinsky", dar continuidade ao estudo dessas sociedades secretas e auxiliar na compreensão e análise da sociedade brasileira.

Quem seriam realmente esses povoadores do interior do Brasil? Quem eram os intrépidos e destemidos homens que se embrenhavam no sertão à procura de metais preciosos? Quais eram suas motivações e sua mentalidade? Encontramos nos documentos diversas pistas para conhecermos a origem do povo brasileiro. Para o Conde de Assumar, (governador das Minas de 1707 a 1721), os imigrantes que se dirigiam para as Minas, eram a "escória da terra".

Charles Boxer diz que devemos ter cuidado com as descrições injuriosas do governador, pois os portugueses eram, na sua maioria, muito pobres, porém, jovens e robustos, vindos principalmente da região do Minho e do Douro. ${ }^{2}$ Além dos novos imigrantes, as Minas foram ocupadas, principalmente, pelos pioneiros paulistas e suas bandeiras à procura de metais preciosos e indígenas.

Uma nova interpretação, de Anita Novinsky, sobre a mentalidade dos paulistas, traz luz ao estudo sobre as motivações dos bandeirantes, além da econômica, e sobre a própria constituição do povo brasileiro. Após a Conversão Forçada (1496) e o estabelecimento da Inquisição em Portugal (1536), o cristão novo procurou fugir de Portugal para a Colônia Brasileira.

O converso, ao chegar no Brasil foi influenciado pelo clima, pela aspereza da vida na floresta, pelos animais selvagens, até então desconhecidos, e pela animosidade dos nativos, que fez emergir um "novo homem", com uma nova compreensão do mundo. Esse homem tornouse um aventureiro, revolucionário, violento e rude. Os pioneiros na região mineradora, entre eles diversos cristãos novos, são exemplos desse "Novo Homem". A sociedade das Minas se formou com características próprias, recebeu mais em outras regiões do Brasil, a influência desse homem destemido e rústico. Resultou da energia desprendida pelos bandeirantes paulistas, em busca de ouro e pedras preciosas e dos fluxos externos de conquista e exploração. O governador Geral Dom João de Lencastre descreveu os paulistas como uma "gente amantíssima da liberdade". ${ }^{3}$ Para os estrangeiros que visitaram o Brasil no período, "os paulistas eram uma gente libertina, que não admite governo", vivendo sob suas próprias leis ${ }^{4}$. Essa opinião reforça a ideia dos paulistas em busca de sua "Nova Canaã" no sertão brasileiro.

Os primeiros povoadores de São Paulo eram tidos como homens rudes, porém alguns tinham certo nível de erudição, como o cristão novo Cosme Fernandes Pessoa, o Bacharel de Cananeia. Há evidências de que população local desprezava a Inquisição e expressava a sua repugnância utilizando frases repetidas constantemente aos brados: "Se chegar um agente do Santo Ofício, será recebido a flechadas". Se trata-se de uma lenda ou não, teremos que deixar para futuras pesquisas..

\footnotetext{
${ }^{1}$ Santos, Lúcio. "A Conjuração mineira: suas causas, seu espírito, seus efeitos. Revista do Archivo Público Mineiro. Instituto Histórico e Geographico de Minas Gerais. V. 22, 1928.

${ }^{2}$ Boxer, Charles. A idade de Ouro no Brasil. Companhia Editora Nacional. São Paulo, 1963, p. 45.

3 "Dom João de Lencastre à Coroa", Bahia, 1 de janeiro de 1700 apud Boxer. A Idade do Ouro no Brasil. Companhia Editora nacional. São Paulo, 1963 p. 48.

${ }^{4}$ Froger, François. A relation of a voyage made in the years 1695, 1696, 1697, on the coasts of Africa, Streights of Magellan, Brasil, Cayenna, and the Antilles, by a squadron of French men of war, under the command of $M$. de Gennes by the Sieur Froger. Printed for M. Gillyflower; W. Freeman, M. Wotton; J. Walthoe; and R. Parker. Londres, 1698 p. 62 in 〈https://quod.lib.umich.edu/e/eebo/A40503.0001.001?view=toc〉.

Dampier, Cap. Willian. A Voyage to New Holland 1699. Printed for James and John Knapton at the Crown in Saint Paul's $\quad$ Churchyard, $\quad$ Londres, 1729 in <https://ia802308.us.archive.org/6/items/avoyagetonewholl15675gut/15675-h/15675-h.htm>.
} 
As Minas nunca foram uma Capitania hereditária, mas sim um território de disputas, composto por diferentes etnias e com espírito de pioneirismo. A fusão das raças e das culturas deu origem à cultura mineradora.

O papel dos cristãos novos nesse envolvimento inicial do ouro foi relevante, e entre eles se sobressaiu Manuel Nunes Viana, que alcançou, posteriormente, tanto prestígio que foi chamado de rei dos Emboabas, por salientar-se na luta entre portugueses e paulistas pelo controle da exploração do ouro nas minas.

Com o descobrimento do ouro, as minas atraíram numerosos indivíduos, muitos dos quais eram recém-chegados de Portugal. A inundação de pessoas na região fez com que surgisse uma acirrada rivalidade entre os pioneiros paulistas, que se declaravam merecedores de privilégios na exploração aurífera, e os novos imigrantes. Por um lado, os paulistas tinham, como líderes, o Superintendente das Minas, Manuel da Borba Gato e o Capitão Jerônimo Pedrozo de Barros, de origem judaica, e do outro lado, defendendo os portugueses e os que vinham de outras Capitanias (Bahia, Pernambuco e Rio de Janeiro), apelidados de "emboabas", estava outro cristão novo, Manuel Nunes Viana. ${ }^{5}$ Pela primeira vez no Brasil, cristãos novos lutavam em facções opostas. Porém, tanto Manuel Nunes Viana quanto Jerônimo Pedrozo e Borba Gato, são típicos exemplos do "Novo Homem". Suas posições antagônicas explicam-se mais pela disputa econômica e pela construção de uma identidade ligada à pátria lusitana por parte dos novos imigrantes, em oposição à formação de uma identidade dos paulistas, que estava mais ligada à sua origem judaica. Diversos foram os exemplos de bandeirantes paulistas, principalmente Raposo Tavares, Pedro Vas de Barros e os irmãos Fernandes, fundadores da região de Sorocaba, que afirmavam ser o sertão do Brasil a sonhada Terra Prometida, a Nova Canaã.

Os paulistas cristãos novos falavam o tupi, tinham escravos ameríndios e estavam à vontade no sertão. Viam a região mineira como sua propriedade, pretendiam ter na Minas e no resto do interior brasileiro, um novo lar. Em 1700, o Conselho da cidade de São Paulo enviou um requerimento ao Rei de Portugal para que as terras das Minas Gerais fossem exclusivamente deles. $^{6}$

O confronto entre Manuel Nunes Viana e Jeronimo Pedrozo teve seu ápice na porta da igreja de Caeté, quando, após a missa de domingo, os dois tomaram partes opostas em um conflito sobre uma espingarda emprestada, iniciaram uma acalorada discussão e Viana desafiou Pedrozo para um duelo, que aceitou, mas depois acabou desistindo. Humilhados, os paulistas planejaram vingança.

Manuel Nunes Viana era conhecido pelo tratamento desrespeitoso com que tratava seus adversários, usando de trocadilhos cômicos, injuriosos e alcunhas ofensivas, descompondo os adversários em praça pública, que, humilhados, buscavam por vingança. Os paulistas, desdenhando de seus inimigos, toda vez que escutavam um estampido de um tiro a distância, bradavam, "lá morreu cachorro ou emboaba". ${ }^{7}$ Com o clima de rivalidade, o pequeno entrevero, parte de um longo processo de enfrentamentos entre paulistas e forasteiros, deu início ao grande confronto que foi a Guerra dos Emboabas. ${ }^{8}$

\footnotetext{
5 Primeira Visitação do Santo Ofício ás partes do Brasil, pelo Licenciado Heitor Furtado de Mendonça (Denunciações da Bahia, 1591-1593). Ed. Paulo Prado. São Paulo, 1924 p. 419-420. Denúncia do filho Antônio Pedrozo de Barros, de que os pais, Jeronimo Pedrozo e Joana Vas de Barros eram meio cristãos novos. Ver também: Salvador, Gonçalves. Os cristãos novos: povoamento e conquista do solo brasileiro. Ed. Pioneira. São Paulo, 1976, p. 32.

${ }^{6}$ Câmara Municipal de São Paulo à Coroa, em 7 de abril de 1700 apud Taunay. História Geral IX, p. $473-474$.

${ }^{7}$ Boxer, Charles. A Idade do Ouro no Brasil. Companhia Editora Nacional. São Paulo, 1963, p. 73.

${ }^{8}$ A Guerra dos emboabas ocorreu entre os anos de 1707 e 1709, entre os bandeirantes paulistas e os emboabas (portugueses e imigrantes de outras regiões do Brasil). O confronto tinha como causa principal a disputa pela exploração das minas de ouro. Os paulistas queriam exclusividade na exploração da região, e mais direitos e benefícios sobre o ouro que haviam encontrado.
} 
Manuel Nunes Viana era um homem de mediana estatura, cara redonda, olhos pardos e cabelo preto, nascido em Viana do Castelo. Chegou na Bahia ainda garoto, mas logo depois seguiu para o interior, com cartas de recomendação do governador da Capitania para alguns criadores de gado no Rio São Francisco, onde passou a administrar a propriedade de D. Izabel Maria, uma das principais latifundiárias do Brasil. Fez fortuna com carregações de gado para as Minas, e em 1707 já era proprietário de várias minas de ouro em Caeté. Durante a Guerra dos Emboabas, Borba Gato ordenou que fosse expulso das minas, porém tornou-se líder do grupo dos portugueses e foi eleito governador das Minas pelos forasteiros.

Devemos mencionar a ligação de Manuel Nunes Viana com as tradições judaicas de seus antepassados. A relação de Viana com o judaísmo se deu através de seu círculo de amizades, que incluía homens de negócio cristãos novos, como o judaizante Miguel de Mendonça Valladolid e o vultuoso comerciante da Bahia, Antônio Cardozo Porto, com quem mantinha negócios.

Miguel de Mendonça Valladolid viveu por alguns anos na Holanda, onde foi circuncidado, frequentava a sinagoga e aprendeu tudo sobre o ritual litúrgico judaico. Como homem de negócio, Antônio Cardozo Porto circulava pelas comunidades judaicas europeias, principalmente na França, onde havia vivido por 16 anos e ainda mantinha negócios, recebendo da comunidade judaica de Bayonne, anualmente, a informação de todas as festividades judaicas.

Com Miguel de Mendonça Valladolid, Manuel Nunes Viana aprendeu as orações judaicas, e através de Antônio Cardozo Porto, era atualizado sobre o calendário das festas e dos dias sagrados para o judaísmo. Vallodolid ensinou a Manoel Nunes Viana uma oração para purificar as mãos: "Bendito tu Adonai Nuestro Dios, Rey del mundo, que nos santificou com suas encomendações sobre a limpeza das mãos" ". Essa é a oração judaica conhecida como Netilat Yadaiym, recitada antes de se lavar as mãos, principalmente ao acordar e antes das refeições.

Os amigos de Manuel Nunes Viana foram presos pela Inquisição portuguesa e tiveram trágico destino. Valladolid saiu em auto de fé com as mãos atadas e foi relaxado à justiça secular, o que significava ser queimado na fogueira. Antônio Cardozo Porto terminou seus dias na miséria, vagando pelo bairro penitencial de Santa Marinha, em Lisboa, onde os sentenciados deveriam morar e ser constantemente vigiados, após passar cinco anos nos cárceres do Santo Ofício. ${ }^{10}$

Diferente destino teve Manuel Nunes Viana. Após derrotar os paulistas, a Coroa portuguesa interferiu, ordenou que Viana retornasse a suas terras no Rio São Francisco, por haver usurpado a autoridade da Coroa. No São Francisco, tornou-se importante líder político, amado, respeitado e muitas vezes temido pelo povo. Aumentou ainda mais sua fortuna, dando continuidade no seu negócio de criação de gado, distribuindo carne para diversas vilas nas Gerais e empregando muitos escravos na mineração. ${ }^{11}$

Para acalmar os ânimos, a Coroa concedeu anistia a ambos os lados, manteve as nomeações feitas por Manuel Nunes Viana e reintegrou Manuel do Borba Gato como Superintendente da região do Rio das Velhas, além de criar a Capitania de São Paulo e das Vilas do Ouro, com sede na cidade de São Paulo.

Já idoso, Manuel Nunes Viana se dedicou à cultura, e durante uma temporada em Lisboa, financiou a primeira edição da obra Peregrinos da América (28 de junho 1725), cujo autor,

Romeiro, Adriana. Paulista e Emboaba no coração das Minas. Ed. UFMG. Belo Horizonte, 2008, p. 91.

${ }^{9}$ ANTT-IL. Processo 9973. Miguel de Mendonça Valladolid

${ }^{10}$ ANTT-IL. Processo 9973. Miguel de Mendonça Valladolid. Fl. 630-637.

ANTT-IL. Processo 8887. Antônio Cardozo Porto

${ }^{11}$ Boxer, Charles. A Idade do Ouro no Brasil. Op. Cit. pp. 79-82. 
Mina Marques Pereira, lhe dedicou as "Suplicas", e, em 1763, pagou a impressão do volume III das "Décadas" de Diogo do Couto. Alfabetizado, tinha uma biblioteca especializada em títulos políticos, como Portugal Restaurado, do Conde de Ericeira, Guerra de Granada hecha por El Rei de España Don Phillippe II contra los mouriscos de aquel reino, sus rebeldes, de Don Diego Hurtado de Mendonza e Luís Tribaldos de Toledo. ${ }^{12}$

Através dos exemplos de Fernão Dias Paes, Manuel da Borba Gato, Jerônimo Pedrozo e Manuel Nunes Viana, podemos afirmar que entre os pioneiros na descoberta do ouro e diamantes no Brasil, e na construção das primeiras vilas do ouro, estavam os sefaraditas, descedentes dos judeus convertidos em 1497.

O filho do bandeirante Fernão Dias com uma cristã nova, Garcia Rodrigues Paes, foi o responsável por encurtar o caminho e reduzir o tempo de viagem entre o Rio de Janeiro (principal porto da colônia) e a vila Ouro Preto. Abriu uma nova estrada, chamada Caminho Novo ou Caminho do Comércio. Havia um entroncamento com a estrada antiga em Pindamonhangaba, e as duas estradas se tornavam uma só e levava cerca de vinte dias até chegar às minas do Rio das Mortes. Com essa nova estrada, tornou-se possível alcançar o interior em cinco dias. Em recompensa aos serviços prestados à Coroa, no ano de 1702, Garcia Rodrigues Paes foi nomeado inspetor-geral e Guarda Mor das Minas e obteve o título de Fidalgo da Casa Real.

Mesmo após toda a contribuição dos cristãos novos para o povoamento do interior brasileiro, foi evocado o Estatuto de Pureza de Sangue, criado em 1449, para distinguir cristãos novos e velhos e restringir a igualdade entre os grupos. O rei precisava limitar o número de pessoas que entrariam nas Minas, e a forma mais fácil para fazer isso seria excluindo o acesso dos cristãos novos; a legislação discriminatória já existia, seria só aplicá-la a esse contexto, estabelecendo a proibição aos cristãos novos de utilizarem as estradas de penetração do Brasil, mesmo tendo sido abertas por um descendente de convertidos.

O distante sertão tornou-se um refúgio também para os cristãos novos paulistas que se sentiam ameaçados pelo Santo Ofício. Como exemplo podemos citar o cristão novo Pedro da Silva, filho de Francisco Rendon, de uma tradicional família paulista. Pedro da Silva seguiu para as Minas logo após sua mãe e sua irmã terem sido denunciadas por uma escrava por práticas judaizantes; seu primo, o clérigo Lourenço Toledo Taques, era conhecido em São Paulo como "mestre da sinagoga", por possuir uma casa ao lado da igreja, onde celebrava os rituais judaicos. ${ }^{13}$ Mas enganou-se Pedro da Silva, e mesmo com uma grande dificuldade no cumprimento das prisões em razão da distância entre as localidades, no extenso sertão das Gerais, a Inquisição fez das Minas a segunda região com o maior número de presos na primeira metade do século XVIII.

Os dinâmicos homens das empresas mercantis, que deram impulso aos negócios do Brasil, tiveram destinos diferentes. Diversos chegaram a ser magnatas, enquanto outros, devido a sua origem judaica, com sentimentos mais arraigados aos costumes dos antepassados, foram presos ou reduzidos à miséria pela Inquisição portuguesa. Como sabemos, no Brasil nunca houve a instalação de um Tribunal do Santo Ofício, somente agentes da Inquisição que investigavam cada ato da vida dos cristãos novos incentivando as denúncias e tornando a confissão quase obrigatória.

A atuação inquisitorial nas novas "vilas do ouro" se deu através das "Devassas Gerais", realizadas por prelados ou visitadores, que atuavam também como agentes inquisitoriais de Lisboa, e através dos Comissários e "familiares" do Santo Ofício, verdadeiros espiões,

\footnotetext{
${ }^{12}$ ROMEIRO, Adriana. Paulista e Emboaba no coração das Minas. Ed. UFMG. Belo Horizonte, 2008, p. 160.

${ }^{13}$ Arquivo Nacional da Torre do Tombo. Inquisição de Lisboa. Livro no 280, Caderno do Promotor 87; Paes Leme, Pedro Taques de Almeida. Nobiliarquia Paulista Histórica e Genealógica. Tomo III. Ed. Itatiaia. São Paulo, 1980.
} 
responsáveis pela instauração de uma rede de delações e denúncias que moviam as engrenagens da Inquisição.

Os sefaraditas acreditavam estar seguros, embrenhados no sertão brasileiro, mas a rede de familiares e comissários alcançou os descendentes dos judeus convertidos e os enviou ao Palácio dos Estaus, em Lisboa, núcleo inquisitorial responsável pelos prisioneiros do Brasil. Toda essa estrutura de espionagem e delação tornou Minas, na primeira metade do século XVIII, a segunda região do Brasil com o maior número de prisões, só ultrapassada pelo Rio de Janeiro. A ilusão dos cristãos novos que vieram para as minas do Brasil, em uma nova etapa do processo de colonização e conquista, acreditando ser esta a terra "do leite e mel", reforçada pela visão singela e tranquila dos escritos dos primeiros cronistas portugueses, terminou com a chegada da malha inquisitorial que levou para os cárceres dos Estaus muitos imigrantes portugueses de origem sefaradita ${ }^{14}$.

\section{Bibliografia}

Arquivo Nacional da Torre do Tombo- Inquisição de Lisboa. Processo 9973. Miguel de Mendonça Valladolid.

Arquivo Nacional da Torre do Tombo- Inquisição de Lisboa. Processo 8887. Antônio Cardozo Porto.

Processo n. 7488. Diogo Nunes.

Processo n. 7487. Diogo Nunes Henriques.

Livro $n^{\circ} 280$, Caderno do Promotor 87.

Primeira Visitação do Santo Ofício as partes do Brasil, pelo Licenciado Heitor Furtado de Mendonça (Denunciações da Bahia, 1591-1593). Ed. Paulo Prado. São Paulo, 1924.

FROGER, François. A relation of a voyage made in the years 1695, 1696, 1697, on the coasts of Africa, Streights of Magellan, Brasil, Cayenna, and the Antilles, by a squadron of French men of war, under the command of M. de Gennes by the Sieur Froger. Printed for M. Gillyflower; W. Freeman, M. Wotton; J. Walthoe; and R. Parker. Londres, 1698, p. 62, in <https://quod.lib.umich.edu/e/eebo/A40503.0001.001?view=toc >.

DAMPIER, Cap. Willian. A Voyage to New Holland 1699. Printed for James and John Knapton at the Crown in Saint Paul's Churchyard, Londres, 1729, in <https://ia802308.us.archive.org/6/items/avoyagetonewholl15675gut/15675-h/15675-h.html>. ARRUDA, Maria Arminda do Nascimento. Mitologia da Mineiridade. Ed. Brasiliense. São Paulo, 1990.

ANTONIL, André João. Cultura e Opulência do Brasil por suas Drogas e Minas. Cap. Vterceira parte (introdução André M. Diniz Silva) Ed. Edusp, 2007, p. 227.

BOGACIOVAS, Marcelo. Cristãos Novos em São Paulo. ASBRAP. São Paulo, 2015

BOXER, Charles. A Idade do Ouro no Brasil. Companhia Editora Nacional. São Paulo, 1963. FURTADO, Junia Ferreira. Homens de negócio: A interiorização da metrópole e do comércio nas Minas setecentistas. São Paulo, ed. Hucitec, 1999.

SILVA, Lina Gorenstein Ferreira. Heréticos e Impuros. Prefeitura da Cidade do Rio de Janeiro. Secretaria Municipal de Cultura. Departamento Geral de Documentação e Inf., s/d.

Levy, Daniela. "A Investida inquisitorial no século dourado" in A Inquisição revisitada. Centro de História e Cultura Judaica (org). Ed. Jaguatirica. Rio de Janeiro, 2015.

\footnotetext{
${ }^{14}$ Levy, Daniela. "A Investida inquisitorial no século dourado" in A Inquisição revisitada. Centro de História e Cultura Judaica (org). Ed. Jaguatirica. Rio de Janeiro, 2015 p. 113-129; Novinsky, Anita. "Marranos e Inquisição: sobre a rota do ouro em Minas Gerais" in Os judeus no Brasil: Inquisição, imigração e identidade. Ed. Companhia Civilização Brasileira. Rio de Janeiro, 2005. P. 161-196.
} 
LIMA, Jr., Augusto de. A Capitania das Minas Gerais. Ed. Itatiaia- Ed. da Universidade de São Paulo. Belo Horizonte/ São Paulo, 1978.

História dos diamantes nas Minas Gerais. Edições Dois mundos -

Livros de Portugal. Rio de Janeiro,1945.

NOVINSKY, Anita. "Marranos e Inquisição: sobre a rota do ouro em Minas Gerais" in Os judeus no Brasil: Inquisição, imigração e identidade. Ed. Companhia Civilização Brasileira. Rio de Janeiro, 2005.

PAES LEME, Pedro Taques de Almeida. Nobiliarquia Paulista Histórica e Genealógica. Tomo III. Ed. Itatiaia. São Paulo, 1980.

ROMEIRO, Adriana. Paulista e Emboaba no coração das Minas. Ed. UFMG. Belo Horizonte, 2008, p. 160.

SANTOS, Lúcio. A Conjuração mineira: suas causas, seu espírito, seus efeitos, em Revista do Archivo Público Mineiro. Instituto Histórico e Geographico de Minas Gerais. V. 22, 1928.

SALVADOR, Gonçalves. Os cristãos novos: povoamento e conquista do solo brasileiro. Ed. Pioneira. São Paulo, 1976.

TAUNAY, Affonso. História Geral das Bandeiras Paulistas IX. Museu Paulista. São Paulo, 1950. 